\title{
Somatoform disorder: a raison d'etre for
}

\section{liaison psychiatry}

\author{
Sean O'Sullivan, Eugene M Cassidy
}

Ir J Psych Med 2006; 23(4): 128-130

\begin{abstract}
Introduction
Although severe somatoform disorders are as common and disabling as schizophrenia, these disorders have been neglected by both psychiatry and medicine. This is unfortunate as appropriate treatment improves outcome and reduces healthcare costs. To ensure availability of such treatments, liaison psychiatry and other services need to continue to develop in healthcare settings across Ireland with a vision that expands beyond the recent 'Vision for Change'. The prevalence, chronicity and level of disability of such patients suggests that the current restricted use of the term ' severe and enduring mental illness' should either be expanded to include severe somatoform disorders or abandoned altogether.
\end{abstract}

Key words: Functional; somatoform; liaison; unexplained.

\section{Unexplained somatic symptoms and syndromes}

Most somatic symptoms are not associated with a clear medical diagnosis or identifiable pathophysiology and are considered 'functional'. Such functional somatic symptoms are common in the general population. In Germany, Rief et al' reported an average of 3.4 symptoms per person over the previous two years for which no medical cause was found and which had a significant influence on well-being. In the US, $10.5 \%$ of the general population reported at least one unexplained physical symptom over the previous year. ${ }^{2}$ In medical outpatient and inpatient settings, functional somatic symptoms appear more common where they account for a disproportionately high use of healthcare resources. ${ }^{3}$ In an epidemiological study in Southeast London, Nimnuan et $a^{4}$ examined the prevalence of functional somatic symptoms in a large cohort ( $n=890$ ) of all new outpatient attenders to seven different medical specialities. In more than half of the sample for whom complete data was available $(n=582)$, the principle somatic complaint was found to be medically unexplained following appropriate examination and investigation. Patients with such symptoms were more likely to be female and younger, and more likely to endorse a physical rather than a lifestyle or psychological attribution for their symptoms.

Functional syndromes (typically groups of unexplained somatic symptoms) have long been observed in patients

Sean O'Sullivan, MB, MRCPI. Clinical Research Fellow, Institute of Neurology, University College London, England. *Eugene M Cassidy, MB, MRCPsych, MMedSc (Physiology), MD. Consultant Liaison Psychiatrist, Cork University Hospital, Wilton, Cork, Ireland.

*Correspondence

SUBMITTED: OCTOBER 27, 2006. ACCEPTED: NOVEMBER 3, 2006. attending different medical specialties. Indeed, almost every medical specialty has its own functional somatic syndrome as a discrete diagnostic entity (eg. fibromyalgia in rheumatology, irritable bowel syndrome in gastroenterology etc.). These syndromes have been the subject of considerable research into possible aetiology \& pathophysiology but in the absence of such explanations, they continue to be defined largely by groups of subjectively reported symptoms and associated disability. Despite the oft-posited co-occurrence of these syndromes in clinical practice, until recently there has been little by way of epidemiological data to support this. In the same cohort of medical outpatients described above, Nimnuan et $a^{5}$ examined the prevalence of 13 different functional somatic syndromes (including fibromyalgia, chronic fatigue syndrome, irritable bowel syndrome, tension headache, atypical facial pain, temporomandibular joint dysfunction, hyperventilation syndrome, non-ulcer dyspepsia, globus syndrome, multiple chemical sensitivity, chronic pelvic pain, premenstrual syndrome). Of the sample 56\% had at least one functional somatic syndrome (FSS) and half of these had more than one. Aggarwal et af recently examined the prevalence and co-occurrence of four functional somatic syndromes (chronic widespread pain, chronic oro-facial pain, irritable bowel syndrome, and chronic fatigue) in a general population survey, $27 \%$ reported one or more syndromes and $1 \%$ reported all four. There were a number of common factors across syndromes including female gender, high levels of aspects of health anxiety, reporting of other somatic symptoms and reporting of recent adverse life events. This finding is in keeping with the observation that among individuals who consult with such unexplained somatic symptoms, psychosocial factors play a major role in maintaining symptoms and disability.

\section{Depression and somatic symptoms}

The prevalence of major depression is high among patients with chronic medical illness. ${ }^{7}$ When it is comorbid, depression is associated with a $50 \%$ increase in medical costs as well as increased morbidity and mortality. Clinical experience also suggests significant co-morbidity of anxiety and depression among those who report somatic symptoms that are medically unexplained. Thus, depression could account for somatic symptom reporting. In a landmark study of $>25,000$ subjects ( $>5000$ of whom were interviewed) carried out by the World Health Organisation in primary care centres across 14 countries in five continents ${ }^{8}$ depression was found to present somatically (rather than psychologically) in the majority of cases. Neither cultural factors nor denial of psychological symptoms explained this robust finding.

Both female gender and having a history of early life trauma (including sexual abuse) are well-established risk factors for 
adult anxiety and depression. It is perhaps not surprising therefore that somatic symptom reporting is more common in females and among those with a history of childhood abuse. ${ }^{9}$ This effect however persists after depression has been controlled suggesting common trait vulnerability to both depression and somatic symptom reporting.

Pain, the most common somatic symptom reported in the general population, is found in a majority of depressives in those studies that have looked for it. For instance, in a large general population survey in five European countries $(n=$ $18,980), 28 \%$ of those with depressive symptoms also had chronic pain and $43 \%$ of those who met criteria for major depression also had chronic pain. Those with pain had more severe depressive disorder. ${ }^{10}$ This finding is even more obvious in healthcare settings. In Canada, more than 3/4 of 685 patients attending primary care for the first time who fulfilled criteria for depression reported painful symptoms ${ }^{11}$ and in France, $92 \%$ of 150 patients about to be hospitalised with major depression had at least one painful symptom. ${ }^{12}$ Therefore depression typically presents somatically and pain appears to be a core feature of depression. In Ireland as elsewhere in the western world, pain medicine services have evolved in most healthcare settings to meet the needs of patients with chronic pain who are increasing in prevalence ${ }^{13}$ and who typically have marked disability. Unfortunately these services have not always been resourced or developed to include access to assessment by a mental health professional.

\section{Somatoform disorders}

Somatoform disorders (including somatisation disorder, conversion disorder and somatoform disorder) are psychiatric disorders that present with unexplained somatic symptoms and disability typically in the general hospital setting. It is generally agreed that the current classification of somatoform disorders in both DSM-IV and ICD-10 is unsatisfactory and requires revision. ${ }^{14-17}$ For instance, many patients with somatoform disorder are classified under the dubious categories of undifferentiated somatoform disorder or somatoform disorder - not otherwise specified. Some authors have even called for radical revision. ${ }^{18}$ Severe somatoform disorders are at least as common (and as disabling) as schizophrenia. ${ }^{19-21}$ Smith et $a^{22}$ found that their cohort of subjects with somatisation disorder (a somatoform disorder characterised by multiple medically unexplained symptoms, including pseudoneurological symptoms, of long duration) spent an average of seven days ill in bed each month and in another cohort, ${ }^{23}$ $10 \%$ were wheelchair-bound. Acute general hospitals with their biomedical emphasis are ill-equipped to deal with such individuals.

Not surprisingly, patients with somatoform disorders incur a disproportionate amount of healthcare costs. In a recent US study, the annual healthcare costs (including inpatient, outpatient, emergency department, specialty and primary care) were doubled in patients with probable somatoform disorder. ${ }^{24}$ These costs were solely due to medical service utilisation as there was no increase in mental health service use by patients with somatoform disorder. This is no surprise as psychiatry, with its growing emphasis on psychotic illnesses, has inevitably neglected this group of patients. ${ }^{25}$ It has been noted that at the American Psychiatric Association
(APA) annual meeting in 2004, there were 220 session titles with the word "depression", 82 with "anxiety", yet only two with "somatoform" and zero with "conversion".26

\section{Somatoform disorders: The role of liaison psychiatry services}

Interventions by adult liaison psychiatry services based in the general hospital setting are demonstrably cost-effective. ${ }^{27}$ ${ }^{29}$ In addition to direct clinical work with such patients, liaison psychiatry services have a role in educating acute healthcare professionals and in advocating a biopsychosocial approach to such patients. Anecdotally, such a role serves to reduce the impact of certain iatrogenic factors that may facilitate disability in somatoform disorders. A key function of the specialty of liaison psychiatry is to reduce distress and improve function of patients with somatoform disorders. Assessment alone of such patients by an appropriate mental health professional has been found to have a positive impact on outcome. ${ }^{30}$ There is now also evidence to support the effectiveness of biological and psychosocial treatments to reduce distress and improve function in patients with somatoform disorders. ${ }^{31-35}$

In Ireland, availability of Liaison Psychiatry services is patchy with $41 \%$ of psychiatrists surveyed in 2004 having no access to liaison psychiatry. ${ }^{36}$ This situation may change as the recent 'Vision for Change' document on mental health service policy has advocated some additional service provision for adult liaison psychiatry. ${ }^{37}$ Given the comparable prevalence of severe somatoform disorder and schizophrenia, the proposed changes though welcome are conservative and could be considered to lack 'vision'. There is also no provision for a national liaison psychiatry inpatient unit that would have dedicated for the assessment, management and rehabilitation of the most complex patients with somatoform disorders.

\section{Somatoform disorders: The role of neuropsychiatry services}

Because such patients typically have disabling pseudoneurological features (including psychogenic non-epileptic seizures and motor conversion disorders), neuropsychiatry services could also address some the needs of patients with somatoform disorders. A significant amount of the work done by clinical neuropsychiatrists is the assessment and management of complex, unexplained neurological symptoms including psychogenic non-epileptic seizures and other chronic conversion disorders. Psychogenic non-epileptic seizures (PNES) are episodes of altered movement, sensation, or experience similar to epilepsy, that are not caused by abnormal electrical discharges in the brain, but rather by psychological processes. The population prevalence of PNES has been estimated to be between two and $33 / 100,000^{38}$ and $10-20 \%$ of presumed intractable epilepsy referred to epilepsy centres have PNES. This suggests that in Ireland there are 80-1,320 individuals with PNES. Patients with PNES, in addition to episodic seizures that mimic epilepsy, typically report pain and other somatic symptoms consistent with somatoform disorder. ${ }^{39}$ Patients with PNES have high rates of medical utilisation, are often treated inappropriately with anticonvulsants and have poor psychosocial outcomes with reduced employment and increased depen- 


\section{brighten \\ someones \\ a simple transition}

in the treatment of

depression that doesn't cost the earth

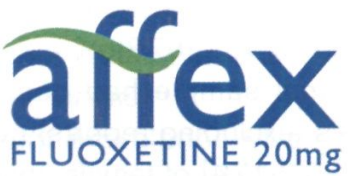

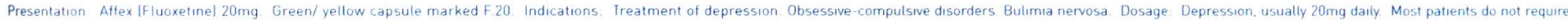

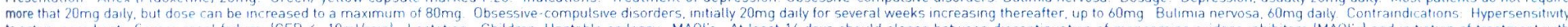

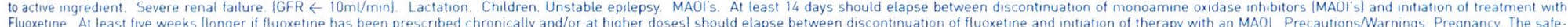

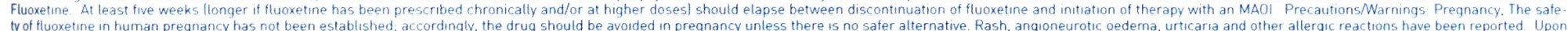

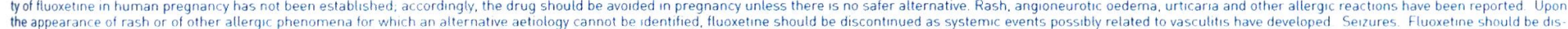

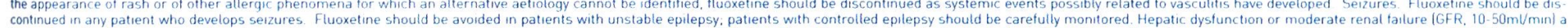

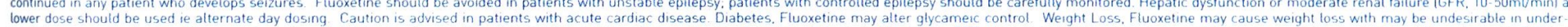

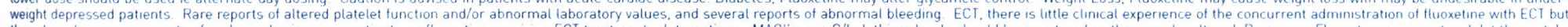

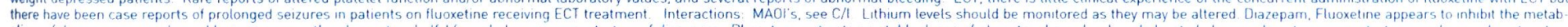

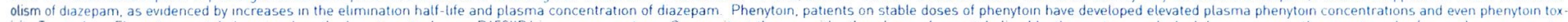

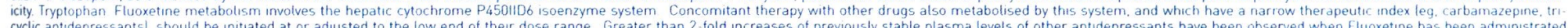

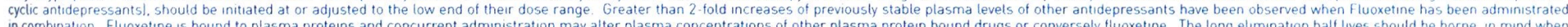

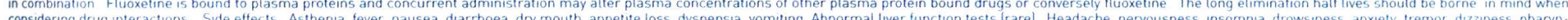

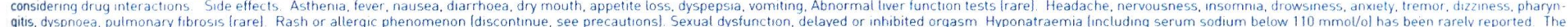

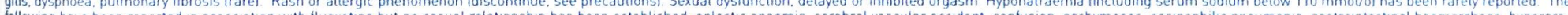

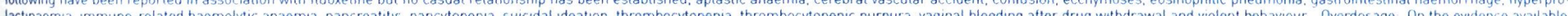

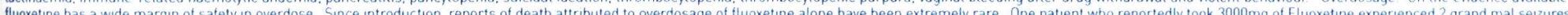

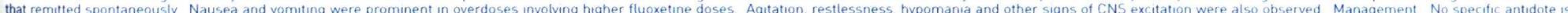
known Packs. Blister Pack of 30 IPA 1241/11/1 L Product Authorisation Holder. Astellas Pharma Co Ltd. 25 The Courtyard. Kilcarbery Business Park. Clondalkin. Dublin 22 Tel L011 4671555 
dency on benefits. ${ }^{40}$ Other causes of neurologically unexplained disability such as chronic motor conversion disorder are not rare, with one UK report yielding a conservative population prevalence estimate for such cases of five per $100,000 .{ }^{41}$ The majority of patients in the study used wheelchairs and all were unemployed.

Despite this clear need, there are virtually no neuropsychiatry services in Ireland. In 2004, almost all (94\%) psychiatrists surveyed had no access to neuropsychiatry services. ${ }^{36}$ There are currently no dedicated inpatient neuropsychiatry beds. While an inpatient neuropsychiatry unit is recommended in the 'Vision for Change' report, it remains to be seen whether patients with somatoform disorders will be prioritised for admission to such a unit.

\section{Conclusion}

Functional somatic symptoms and somatoform disorders are common, costly and largely neglected by both psychiatry and medicine. Although treatments are available that improve outcome and reduce healthcare costs, the needs of the majority of individuals with somatoform disorders are unmet. To address this, appropriately resourced multidisciplinary liaison psychiatry services need to continue to develop in healthcare settings across Ireland. Dedicated inpatient beds and neuropsychiatry services will also be necessary if the needs of the most disabled patients with severe somatoform disorders are to be met. The prevalence, chronicity and level of disability of such patients suggests that the current restricted use of the term 'severe and enduring mental illness' (a term employed liberally in relation to psychotic illness in the 'Vision for Change' report), should either be expanded to include severe somatoform disorders or abandoned altogether.

\section{Declaration of Interest: None}

\section{References}

1. Rief W, Hessel A, Braehler E. Somatization symptoms and hypochondriacal features in the general population. Psychosom Med 2001; 63(4): 595-602. 2. Kirmayer LJ, Robbins JM. Patients who somatise in primary care: a longitudinal study of cognitive and social characteristics. Psychol Med 1996; 26(5): 937-5.

3. Reid S, Wessely S, Crayford T, Hotopf M. Frequent attenders with medically unexplained symptoms: service use and costs in secondary care. $\mathrm{Br} J$ Psychiatry $2002 ; 180: 248-53$

4. Nimnuan C, Hotopf M, Wessely S. Medically unexplained symptoms: an epidemiological study in seven specialities. J Psychosom Res 2001; 51(1): 361-7 5. Nimnuan C, Rabe-Hesketh S, Wessely S, Hotopf M. How many functional somatic syndromes? J Psychosom Res 2001; 51(4): 549-57.

6. Aggarwal VR, McBeth J, Zakrzewska JM, Lunt M, Macfarlane GJ. The epidemiology of chronic syndromes that are frequently unexplained: do they have common associated factors? Int J Epidemiol 2006; 35(2): 468-76.

7. Katon WJ. Clinical and health services relationships between major depression, depressive symptoms, and general medical illness. Biol Psychiatry 2003; 54(3): 216-26.

8. Simon GE, VonKorff M, Piccinelli M, Fullerton C, Ormel J. An international study of the relation between somatic symptoms and depression. N Engl J Med 1999; 341(18): 1329-35.

9. Newman MG, Clayton L, Zuellig A, Cashman L, Arnow B, Dea R, Taylor CB. The relationship of childhood sexual abuse and depression with somatic symptoms and medical utilisation. Psychol Med 2000; 30(5): 1063-77.

10. Ohayon MM, Schatzberg AF. Using chronic pain to predict depressive morbidity in the general population. Arch Gen Psychiatry 2003; 60(1): 39-47.

11. Kirmayer LJ, Robbins JM, Dworkind M, Yaffe MJ. Somatisation and the recognition of depression and anxiety in primary care. Am J Psychiatry 1993; 150(5): 734-41.

12. Corruble E, Guelfi JD. Pain complaints in depressed inpatients Psychopathology. 2000; 33(6): 307-9.

13. Harkness EF, Macfarlane GJ Silman AJ, McBeth J. is musculoskeletal pain more common now than 40 years ago?: Two population-based cross-sectional studies. Rheumatology (Oxford) 2005; 44(7): 890-5.

14. Rief W, Hiller W. Toward empirically based criteria for the classification of somatoform disorders. J Psychosom Res 1999; 46: 507-18.

15. Sharpe M, Carson A. Unexplained somatic symptoms, functional syndromes, and somatisation: do we need a paradigm shift? Ann Intern Med 2001; 134: 926-30. 16. Wise TN, Birkett-Smith $M$. The somatoform disorders for DSM-V: the need for changes in process and content. Psychosomatics 2002; 43: 437-40.

17. De Gucht V, Fischler B. Somatization: a critical review of conceptual and methodological issues. Psychosomatics 2002; 43: $1-9$.

18. Mayou R, Kirmayer LJ, Simon G, Kroenke K, Sharpe M. Somatoform disorders: time for a new approach in DSM-V. Am J Psychiatry 2005; 162: 847-55.

19. Escobar JI, Manu P, Matthews D, Lane T, Swartz M, Canino G. Medically unexplained physical symptoms, somatisation disorder and abridged somatisation studies with the Diagnostic Interview Schedule. Psychiatr Dev 1989; 7(3): 235-45 20. Spitzer RL, Kroenke K, Linzer M, Hahn SR, Williams JB, deGruy FV 3rd, Brody $D$, Davies M. Health-related quality of life in primary care patients with menta disorders. Results from the PRIME-MD 1000 Study. JAMA 1995; 274(19): 1511-7. 21. Hiller W, Rief W, Fichter MM. How disabled are patients with somatoform disorders? Gen Hosp Psychiatry 1997; 19(6): 432-8.

22. Smith GR Jr, Monson RA, Ray DC. Patients with multiple unexplained symptoms Their characteristics, functional health, and health care utilisation. Arch Intern Med 1986; 146(1): 69-72.

23. Bass $\mathrm{C}$, Murphy M. Somatisation disorder in a British teaching hospital. Br J Clin Pract 1991; 45(4): 237-44.

24. Barsky AJ, Orav EJ, Bates DW. Somatisation increases medical utilisation and costs independent of psychiatric and medical comorbidity. Arch Gen Psychiatry 2005; 62(8): 903-10.

25. Bass C, Peveler R, House A. Somatoform disorders: severe psychiatric illnesses neglected by psychiatrists. Br J Psychiatry 2001; 179: 11-4.

26. Benbadis SR. The problem of psychogenic symptoms: is the psychiatric community in denial? Epilepsy Behav 2005 Feb; 6(1): 9-14.

27. Hosaka et al. General Hospital Psychiatry from the perspective of medical economics. Psychiatry Clin Neuroscience 1999; 53(4): 449-53

28. Pritchard $\mathrm{C}$ et al. Two-year prospective study of psychosocial outcomes and a cost-analysis of 'treatment-as-usual' versus an 'enhanced' (specialist liaison nurse) service for aneurysmal sub arachnoid haemorrhage (ASAH) patients and families. $\mathrm{Br} J$ Neurosurg 2004; 18(4): 347-56.

29. Strain JJ et al. Cost offset from a psychiatric consultation liaison intervention with elderly hip fracture patients. Am J Psych 1991; 148: 1044-1049.

30. Smith GR Jr, Rost K, Kashner TM. A trial of the effect of a standardised psychiatric consultation on health outcomes and costs in somatising patients. Arch Gen Psychiatry 1995; 52(3): 238-43

31. Kroenke K, Swindle R. Cognitive-behavioral therapy for somatisation and symptom syndromes: a critical review of controlled clinical trials. Psychother Psychosom 2000; 69(4): 205-15.

32. Barsky AJ, Ahern DK. Cognitive behavior therapy for hypochondriasis: a randomised controlled trial. JAMA 2004; 291: 1464-1470.

33. Shapiro AP, Teasell RW. Behavioural interventions in the rehabilitation of acute v. chronic non-organic (conversion/factitious) motor disorders. Br J Psychiatry 2004; 185: $140-146$

34. Muller T, Mannel M, Murck H, Rahlfs VW. Treatment of somatoform disorders with St. John's wort: a randomised, double-blind and placebo-controlled trial. Psychosom Med 2004; 66:538-547.

35. O'Malley PG, Jackson JL, Santoro J et al. Antidepressant therapy for unexplained symptoms and symptom syndromes. Journal of Family Practice 1999; 48: 980-990. 36. O'Keane V, Jeffers A, Moloney E, and Barry S. Irish Psychiatric Association survey of psychiatric services in Ireland. Psychiatr Bulletin 2004; 28: 364 - 367. 37. A vision for change. Report of the expert group on mental health policy. Department of Health and Children. Dublin: Ireland, 2006.

38. Benbadis SR, Allen Hauser W. An estimate of the prevalence of psychogenic non-epileptic seizures. Seizure 2000; $9(4): 280-1$.

39. Reuber M, House AO, Pukrop R, Bauer J, Elger CE. Somatisation, dissociation and general psychopathology in patients with psychogenic non-epileptic seizures. Epilepsy Res 2003; 57(2-3):159-67.

40. Reuber M, Elger CE. Psychogenic nonepileptic seizures: review and update Epilepsy Behav. 2003;4(3):205-16.

41. Allanson J, Bass C, Wade DT. Characteristics of patients with persistent severe disability and medically unexplained neurological symptoms: a pilot study. J Neurol Neurosurg Psychiatry. 2002;73(3):307-9. 